surgery, combined therapy, the treatment of bacterial endocarditis, the dangers of antibiotic treatment, the laboratory control and uses of antibiotics, and finally the search for new ones. Space precludes individual mention of all of the contributions, but it is hoped that enough has been said to whet the reader's appetite for a most valuable collection of essays.

\section{MARY BARBER.}

Textbook of Microbiology, 17th ed. By William Burrows ; with the collaboration of Richard Janvier Porter and James William Moulder. (Pp. xxiii+ 954 ; 301 figures. 98s.) Philadelphia and London: Saunders. 1959.

The 17th edition of Burrows' textbook maintains the high standard of its predecessors both in production and in the excellent survey it gives of every aspect of a rapidly advancing field. In many respects it can be compared only with two other American publications of the past two years, namely Zinsser's Bacteriology, 11th edition, 1957, and Dubos's Bacterial and Mycotic Infections of Man, 3rd edition, 1958. With the others it attempts, and very largely succeeds, in condensing into less than 1,000 pages all the most important work, beginning with cytology, thence through metabolism and immunity, to a study of the microbes themselves and their special role as disease agents. Especially useful are the clear and very readable accounts of bacterial metabolism, chemotherapeutic drugs and of variation and resistance, all of which have become increasingly important to bacteriologists.

Because of their size and the vast amount of detailed information given, books such as that under review must rank as reference works, indispensable to the laboratory worker but useful both to the teacher and student for the invaluable summaries which they contain. This textbook is too comprehensive for the medical student, unless he wishes to make microbiology his special study, and the same is true for clinical workers. One feels that in places the needs of the latter have been neglected, as in the following example. Staphylococcal cross-infection in hospitals is now a widespread and serious problem everywhere. The control of such infections and a study of their epidemiology by such measures as phage-typing are of immense importance to the clinical worker, yet the matter is hardly mentioned in the volume reviewed, a very serious omission which should be remedied in this and all other textbooks which hope to be of help and interest to the clinical pathologist.

\section{(Late) E. S. DuthiE.}

Bacteriology for Students of Dental Surgery, 2nd ed. By R. B. Lucas and Ivor R. H. Kramer. (Pp. viii + 288 ; 1 colour plate and 58 figures. 27s. 6d.) J. and A. Churchill. London. 1959.

This excellent little book contains all the information needed by the dental student on microbiology. The subject is approached from the medical rather than a narrow dental point of view, and there is an accurate, though necessarily brief, description of the major pathogens. One feels that the condemnation of the now discredited focal sepsis theory could be more outspoken, particularly as it is going to be read by future dental surgeons. The section on subacute endocarditis stresses the importance of dental hygiene in the evolution of this malady, but omits to suggest that antibiotic administration before and after dental treatment in patients with valvular disease might reduce the dangers of this serious condition. The book is nicely produced and illustrated, and the authors deserve praise for a fine piece of work.

S. D. EleK.

Clinical Chemical Pathology, 2nd ed. By C. H. Gray. (Pp. viii +160 ; 28 figures. 14s.) London: Edward Arnold. 1959.

Professor Gray has revised and improved his popular little book on chemical pathology for its second edition. He has deleted many out-of-date methods of investigation (an example which could be followed by other textbook writers) and could still have deleted more. The U.M.I. of Heilmeyer and the Takata-Ara reaction have had their day, and the augmented histamine test should be standard practice. The information is sound, recent, and well presented, and the book is extremely lucid and readable, which would make it especially welcome for students. Pathologists will find it particularly useful in the selection of appropriate biochemical tests, and for support in advising clinical colleagues on the lack of value of rarely performed complex investigations. The guides to further reading can be commended.

The sections on diabetes and on liver function are particularly good ; indeed, this contributes to the only real criticism of the book, namely a lack of balance. If Professor Gray had written other sections to the same scale as these, then he would have given us a textbook which could have been unreservedly recommended; but he would then have had to expand Protein seems particularly neglected, and the electrophoretic patterns (p. 136) are not typical; where are the usually low albumin of myelomatosis, and the high $\alpha_{2}$ globulin and low $\gamma$-globulin of the nephrotic syndrome? I also would not agree that analysis of serum potassium is of no value in investigating potassium depletion. Some of the terminology could be changed for the next edition, e.g., g. not gm.; proteinuria not albuminuria; not pint as equivalent to $500 \mathrm{ml}$.

Misprints are very few (I noticed 1 instead of 10 in the normal range of transaminases), and the book is. cheap, well produced, and easy to handle. It should. find a place in many a white-coat pocket.

\section{N. BARON.}

Protides of the Biological Fluids, 6th Colloquium 1958. Edited by H. Peeters. (Pp. ix $+330 ; 171$ figures, 60 tables. 45s.) London: D. Van Nostrand. 1959.

Every year since 1953 a conference has been held

in Bruges and is concerned with proteins and electro- 
phoresis. The first volume was small but has grown in size each year, so that now a book of some 300 pages is needed to cover the proceedings. Scientists from all over Europe pool their knowledge, and the meeting in 1958, the report of which is covered in this book, reveals how far the subject has grown. All chemical pathologists should certainly read it and will profit considerably.

The papers are recorded in one of three languages -French, German, and English-but there is a summary in English at the end of each communication. These reports are divided into those on general topics, on techniques, on macroglobulins, on various protein fractions associated with reproduction and on the digestive system and on proteins in disease. There are also reports on two round-table conferences held during the meeting. The standard of presentation is high, and it would be invidious to select a few as being of special merit, for so many are worthy of consideration. The detailed study of the papers will be of invaluable help to all those working on proteins and on electrophoresis.

J. N. Cumings.

Chemical Quantitation of Epinephrine and Norepinephrine in Plasma. By William Muir Manger, Khalil G. Kakim, and Jesse L. Bollman. (Pp. xiv +398 ; 41 tables, 70 figures, 3 appendices. 87s. 6d.) Oxford: Blackwell Scientific Publications; Illinois. Charles C. Thomas. 1959.

The amount of adrenaline and noradrenaline circulating in plasma is minute-of the order of a few micrograms per litre. As might be expected, chemical methods of assay are difficult, exacting, and tedious. Most pharmacologists tend to view them with some suspicion, for when it comes to the final criterion, the biological activity of the substance estimated, there are often marked discrepancies between results obtained by chemical and pharmacological assay.

The authors, who, to give them credit, are well aware of these limitations, have used one of the best of the chemical methods available, the fluorimetric technique of Weil-Malherbe and Bone, to carry out an exhaustive and painstaking study of plasma levels in a variety of clinical and experimental conditions.

Despite the unfortunate delay in publication, which has precluded mention of much of the latter-day break-through in the field of caechol amine metabolism, this is a useful book for the specialist.

\section{SANDler.}

Experimental Allergic Encephalomyelitis and the "Auto-Allergic" Diseases. By Byron H. Waksman. (Pp. 87; 30 figures; Sw. Fr. 15.) Basel and New York: S. Karger. 1959.

This monograph, published as a supplement to Volume 14 of the International Archives of Allergy and Applied Immunology, surveys in its first part the pathology of experimental allergic diseases. Experimental allergic encephalomyelitis, neuritis, auto-allergic diseases of the lens, uveitis, orchitis, thyroiditis, and iso-immune adrenalitis are described; and clinical conditions with features resembling these experimental lesions, such as demyelinating diseases and post-vaccinal encephalomyelitis, mumps orchitis, Hashimoto's disease, and non-tuberculous granuloma of the suprarenal glands, are discussed.

The second part of the monograph is devoted to a discussion of the nature and pathogenesis of "auto-allergic" disease, that is, disease arising as a result of an immunological response to an individual's or species' own tissue. Immunologically speaking, the experimental conditions are all regarded as examples of delayed hypersensitivity, with the same fundamental lesion. Though the antigens are structurally very different (thyroglobulin, lens protein, proteolipid of myelin, and carbohydrate of sperm), Dr. Waksman considers that they have one major point of similarity, separation from the vascular bed and the connective tissue by more or less impermeable cellular barriers, such as the pial-glial membrane and the follicular thyroid epithelium, or by poor lymphatic drainage. This physiological remoteness, together with perhaps the special nature of their metabolism, prevents the antigens from reaching the blood stream in more than negligible concentrations, so that the immune apparatus treats them as foreign substances. If delayed reactivity results from this an "autoallergic" disease process develops, in which a perivenular inflammatory reaction of mononuclear cells is the primary event, with a secondary parenchymal destruction. As the antigen persists, the disease tends to be prolonged or remittent.

Immunological evidence for the clinical parallels of most of the conditions discussed, with the possible exceptions of phako-anaphylactic endophthalmitis and Hashimoto's disease, is, as Dr. Waksman points out, far from conclusive. The still obscure mechanism of action of adjuvants deserves more discussion. The literature of the subject is surveyed fairly extensively, though remarks such as "but see $213 \mathrm{a}$ " and "the recent status of this disease is described in $(196,204$, 208)" are not helpful. Otherwise this is a useful introduction to the literature of a difficult subject of increasing interest.

\section{Treip.}

Coronary Heart Disease. By J. W. Gofman. (Pp. $x x+353$. 60s.) Oxford: Blackwell Scientific Publications ; Springfield, Fllinois: Charles C. Thomas. 1959.

There are many books concerned with the coronary circulation. This is unlike any of the others, for it is exclusively about the aetiological theories of coronary artery disease. Not only from the clinical but also from the epidemiological outlook these theories are notoriously difficult to understand and correlate. Dr. Gofman very fairly quotes a large number of papers and tries to produce a reasoned approach to the prevention of coronary heart disease. He considers blood lipid factors, hypertension, the production of future clinical coronary disease, familial aspects, age, sex, obesity, diet, smoking, "hormones," stress, and possibilities of prevention. 